\title{
IDS set to restart international dental market
}

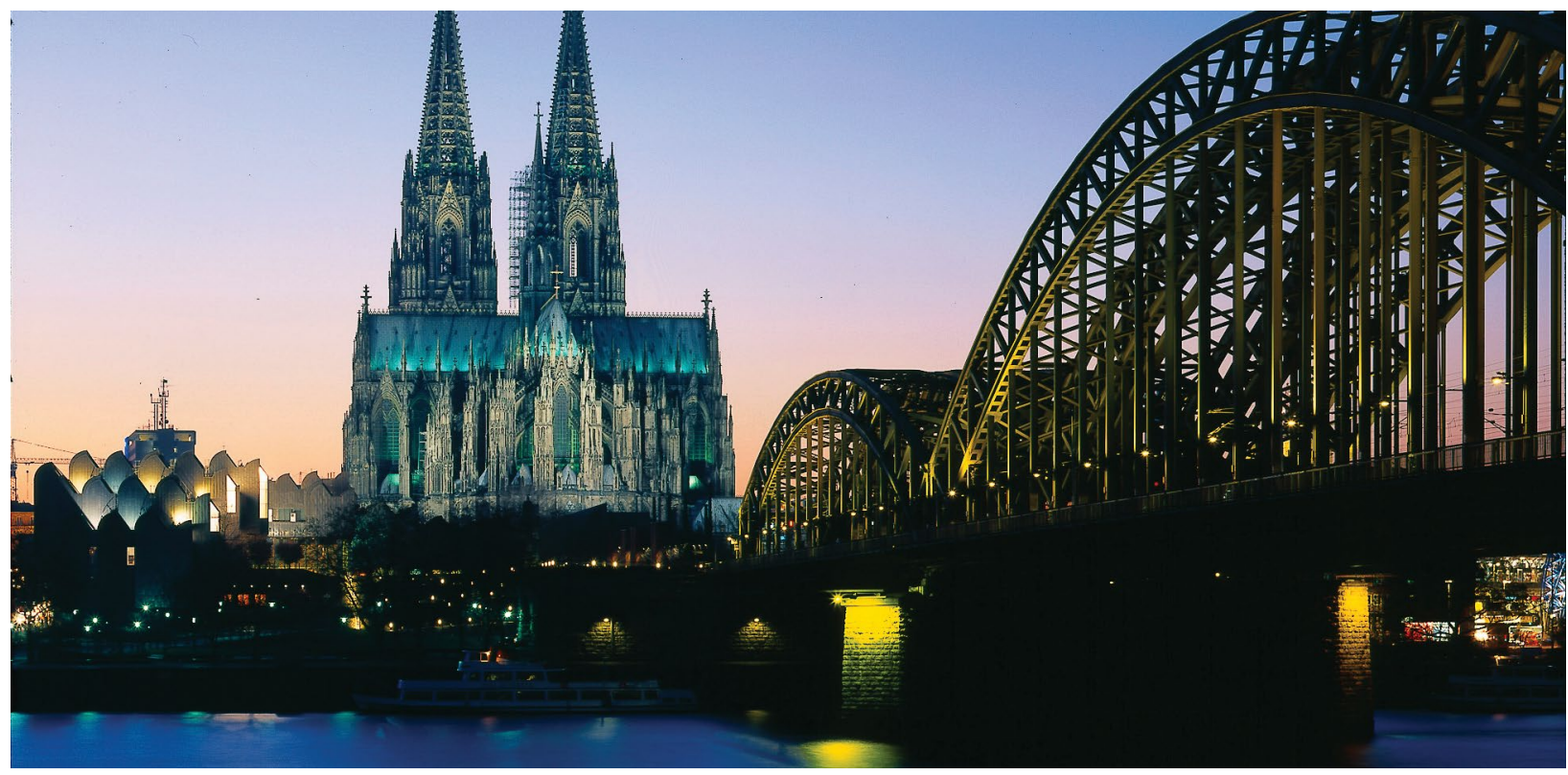

The International Dental Show (IDS) is opening its doors for the 39th time from 22 to 25 September 2021. IDS is playing a key role in the successful restart of the international dental market. At the same time, IDS is also setting new conceptrelated benchmarks. The global trade fair is combining the strengths of a physical event with trailblazing digital features in the form of IDSconnect. The hybrid approach enables professionals from the dental world to discover attractive trade fair presences and products and connect with relevant contact partners via innovative channels.
Around 830 companies from over 56 countries are expected in Cologne for the international trade fair for dentistry and dental technology this September. Seventyfour percent of the exhibitors come from abroad. In addition to Germany, the most strongly represented countries include France, Great Britain, Italy, Korea, Switzerland and the USA. Companies from Brazil, Bulgaria, China, France, Italy, Korea, Russia and the USA are participating at group stands.

IDS 2021 is being staged in Halls 2, 3, 10 and 11 of the Koelnmesse exhibition centre. All halls are connected via a simple circular route. Four entrance areas - the South, East and West entrances and the entrance on the trade fair Boulevard - ensure that the visitors will be evenly distributed throughout the exhibition halls. In addition to the existing restaurant and resting areas in the halls, which are being extended with additional space to ensure the social distancing rules can be adhered to, a new food service area is being installed in Hall 4.1. The hall planning accommodates all necessary measures and official requirements for the protection of exhibitors and visitors.

For more information visit: https://www. english.ids-cologne.de/.

\section{BDA Chairside: conversations about careers in dentistry}

The British Dental Association's (BDA's) new podcast series explores the unlimited, unexpected and maybe even unknown opportunities that qualifying as a dentist open up.

In BDA Chairside, you can join host, Andrea Ogden GDP, as she chats to dental professionals from across the UK who discuss the paths they took that changed the course of their careers.

Over six episodes, speakers cover the topics that so many young dentists and undergraduates say they would like: everything from specialty training, running a business, mixing up careers with non-clinical roles to undertaking FD/VT training, working with children, the CDS and within prisons and even leaving UK clinical dentistry entirely.

These are frank, honest and inspiring conversations that reveal just how much flexibility, opportunity and variety there is within the world of dentistry.

The podcasts are available on all major platforms including Apple, Spotify, Google and Podbean. Search 'BDA Chairside'.

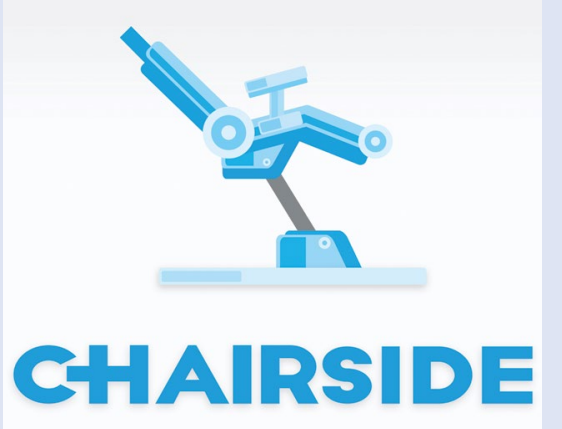

$\underline{B D A}$ 